\title{
Comparison of platelet counts in platelet-rich plasma (PRP) obtained by two methods from dogs"1)
}

\author{
DUYGU DALĞIN, YÜCEL MERAL, METIN ÇENESIZ*, ÇAĞATAY ESIN, \\ BAŞAR ULAŞ SAYILKAN, ÜMIT ÖZCAN, ZEYNEP NURSELIN ÇOLAK, EMRE KÜLLÜK
}

Department of Internal Medicine, *Department of Physiology, Faculty of Veterinary Medicine, Ondokuz Mayıs University, Atakum, 55139, Samsun, Turkey

Dalğın D., Meral Y., Çenesiz M., Esin Ç., Sayılkan B. U., Özcan Ü., Çolak Z. N., Küllük E. Comparison of platelet counts in platelet-rich plasma (PRP) obtained by two methods from dogs

\section{Summary}

Platelet-rich plasma (PRP) is widely used in human medicine, but seldom used in veterinary practice. Even so, the efficacy of PRP in osteoarthritis, dental implants, bone defects and wound healing in dogs and horses is well documented. There are many commercially available PRP tubes and kits for horses and humans, but studies on the effectiveness of these products in dogs are limited. Researches have demonstrated that systems developed for humans and horses do not always produce the same results in dogs. In the present study, two prevailing systems, a sodium citrate-based system and a gel-based system, were compared in terms of their platelet output. The data obtained revealed that, although there was no statistically significant difference between the two systems, the sodium citrate-based kit is probably more efficient in practice due to its superiority in volume output. PRP is an important component of regenerative therapy. It is autologous and practical, but has not been sufficiently implemented in veterinary practice, but promising clinical satisfaction and must be considered in various conditions.

Keywords: autologous, dog, platelet-rich plasma (PRP), regenerative medicine

Platelet-rich plasma (PRP) may be defined as a highly concentrated plasma solution derived from the patient's own blood. The first report on PRP efficacy in tissue healing was published in 1998 by Marx R. E., a dentist, who described its use in the treatment of human mandibular defects (17). Today PRP is used widely to stimulate the healing of complex wounds, in oral surgery, $(22,29)$, in the treatment of tendinopathies, ligament injuries (7), bone fractures (19), and arthritis (5), in anti-inflammatory and acne treatments, as well as in esthetic dermatology, to treat facial wrinkles and hair baldness $(11,14,20,23)$. The method acts by activation of local cells, so applications are local.

There are three types of granules identified among platelets: alpha granules, dense granules and lysosomes $(8,16,27)$. These growth factors modulate cell proliferation, differentiation, angiogenesis and chemotaxis. PRP has been used in regenerative medicine since the discovery of its effectiveness in tissue regeneration. It is widely used due to its commercial availability, its autologous character avoiding immune response, fast and easy application, low cost compared

This research was supported by the Ondokuz May1s University Scientific Research Projects Comission (PYO.VET.1901.17.013). to other regenerative medicine methods and high effectiveness (23).

PRP is relatively new in veterinary medicine (3), but is occasionally used in dogs and horses with osteoarthritis $(1,9)$, dental implants $(25)$, bone defects $(12)$ and wounds (13). PRP injections are highly efficacious especially in decubitis, dermal ulcers, burns, extensive post-operation wounds, wounds due to systemic disorders (diabetes mellitus, etc.), delayed healing, and recurrent wounds in behavioral disorders, such as tail chasing syndrome.

The key factor for a successful PRP application is the cell count in the end product. Studies show that an ideal PRP product must include 4-7 times as many platelets as circulating blood does $(6,18,21)$. Apart from the platelet number, mononuclear cell count, as well as neutrophil and erythrocyte numbers also affect the anti-inflammatory effects and therapeutical success of PRP injections $(6,15,21)$. Generally, pure platelet preparations, without erythrocyte and leucocyte cells, are preferred in order to avoid inflammatory effects $(2,26)$.

There are many commercially available PRP kits prepared for use in humans and horses by different PRP 
separation systems, and different systems result in end products with different platelet, leucocyte and growth factor concentrations $(4,21)$. There are limited studies on the usefulness of these human and horse kits in dogs, since research demonstrated that these kits may not create the same results in dogs (24). There are very few studies investigating the usefulness of human PRP kits in dogs $(3,10)$.

The aim of this study was to compare the end products obtained from dogs by two different (gel-based and sodium citrate-based) PRP kit systems developed for human medicine.

\section{Material and methods}

Ethical approval. This study was approved by the Ondokuz May1s University Animal Studies Local Ethical Committee (approval number B.30.2.ODM.0.20.09.00-050.04).

Animal material. The study material consisted of 15 dogs referred with recurrent wounds or delayed healing due to various causes, such as decubitis, skin ulcers, burns, postoperative wounds, diabetes complications and tail chasing syndrome or traumas. Indications for PRP were determined in 15 dogs following detailed history taking, physical and dermatological examinations, including wound inspection for contamination and complications, and detailed laboratory examinations for systemic disorders.

PRP kit systems. Two different PRP systems were used in the study. The first system, a T-Lab PRP kit (T-Biyoteknoloji Ltd), was a $10 \mathrm{ml}$ tube containing sodium citrate for the prevention of coagulation and it was licensed for clinical applications. Tubes were gamma-sterile and did not contain ficoll or gel.

The second system, a DPG PRP kit (Dermoaroma Inc., Italy), contained alkyl acrylate crosspolymer-based separating gel (inert separator gel) and was also licensed for clinical use.

Both systems are available globally.

Preparation of the PRP product. Venous blood was collected into each tube in both systems simultaneously and processed according to the producers' manual. Cell counts for each tube were recorded by a cell counter, and the end products were applied with dermal needles locally at the site of wounds.

Statistical analyses. Standard error, standard deviation, and average values for both groups and differences between the two groups were calculated by Student's t-test (14).

\section{Results and discussion}

Platelet counts for both systems and a statistical comparison of the two systems are presented in Tables 1 and 2 , respectively.

There are a number of commercially available PRP tubes and kit systems for huamans and horses. These kits differ in their cell separation systems, and therefore also in the platelet, white blood cell, red blood cell and growth factor concentrations in the end products $(4,21)$. There are limited studies on the effectiveness
Tab. 1. The amount of platelets obtained by using the Tlab system and the DPG system in $/ \mu \mathrm{L}$

\begin{tabular}{|c|c|c|}
\hline Specimen & 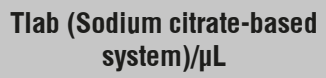 & DPG (Gel-based system)/ $/ \mathrm{L}$ \\
\hline 1 & 572000 & 388000 \\
\hline 2 & 604000 & 876000 \\
\hline 3 & 156000 & 214000 \\
\hline 4 & 150000 & 194000 \\
\hline 5 & 110000 & 152000 \\
\hline 6 & 288000 & 280000 \\
\hline 7 & 266000 & 254000 \\
\hline 8 & 252000 & 264000 \\
\hline 9 & 550000 & 462000 \\
\hline 10 & 800000 & 300000 \\
\hline 11 & 440000 & 360000 \\
\hline 12 & 620000 & 410000 \\
\hline 13 & 580000 & 400000 \\
\hline 14 & 720000 & 510000 \\
\hline 15 & 550000 & 420000 \\
\hline
\end{tabular}

Tab. 2. Statistical comparison of the systems

\begin{tabular}{|c|c|c|}
\hline$n$ & $\begin{array}{c}\text { TLAB (Sodium citrate-based system) } \\
(\overline{\mathrm{x}} \pm \text { SD) }\end{array}$ & $\begin{array}{c}\text { DPG (Gel-based system) } \\
(\overline{\mathrm{x}} \pm \text { SD) }\end{array}$ \\
\hline 15 & $443866.7 \pm 222112.5$ & $365600 \pm 174206.3$ \\
\hline
\end{tabular}

Explanation: the difference is statistically significant at $p \leq 0.05$ level.

of these systems, developed for humans and horses, in canine species, and some studies demonstrated that these systems may not produce the same results in dogs (24). The literature suggests that an ideal PRP product must contain 4-7 fold of the normal platelet count $(18,21)$. In the present study, the optimal number was achieved by both systems, so both of them are suitable for dogs in that respect.

Few studies have been published on the effectiveness of commercially available human kit systems in $\operatorname{dogs}(3,10)$. Carr et al. (3), performed the most extensive study and put emphasis on obtaining blood from the same dog by different systems. In their study, too many systems were compared, so sampling could not be achieved from the same dog, and the authors underlined this fact as the major limitation of the study. In the present study, only two systems were compared, so reliable results were obtained.

One of the crucial points in PRP techniques is acquiring a sterile product, and manuel methods without kits present a bacterial contamination risk during the preparation procedure $(20,28)$. Many products do not contain anticoagulant, so it needs to be added. This creates an important contamination risk together with a risk of preparing a wrong amount of the anticoagulant. In the present work, the citrate-based system included anticoagulant, which eliminated the con- 
tamination risk and can be considered as an important advantage.

During the centrifugation process, cells are subjected to a gravity force of $1.500 \mathrm{G}$ and are separated according to their molecular weights. This procedure makes it possible to obtain PRP, but it also causes platelet aggregation, which is a risk for therapeutic success $(5,15,16,27)$. With this aggregation, a homogenous distribution cannot be achieved. In the citrate-based system used in the present study, the re-suspension tube provided in the kit ensures a homogenous distribution of platelets, which is another therapeutic advantage.

Different amounts of blood must be obtained in different systems, but the volume of blood obtained and the number of platelets acquired do not always correlate. For example, Carr et al. (3), who compared five different systems, reported that blood sample volumes were $50,16,50,9$, and $55 \mathrm{ml}$, whereas PRP product volumes derived were 10, 4-7, 4, 4-5, 6-8 ml, respectively. On the other hand, regarding the platelet numbers obtained, the first, second, and third systems yielded the most efficient products, respectively. Yet, according to the blood volume obtained, the system yielding the highest volume of the product was the third system, which was the worst option in terms of efficiency. In the present study, no statistical differences were recorded between the two systems regarding the number of platelets derived.

In conclusion, although there were no statistical differences between the two systems regarding the platelet content, the sodium citrate-based system appeared more beneficial considering the end product volume and lower contamination risk. Also, in PRP application, the key factors for a successful therapy in practice are the cell count procedure, product selection according to the species, and maximum attention to asepsis.

\section{References}

1. Bosch G., van Schie H. T. M., Groot M. W., Cadby J. A., van de Lest C. H. A., Barneveld A. B., van Weeren P. R.: Effects of platelet-rich plasma on the quality of repair of mechanically induced core lesions in equine superficial digital flexor tendons: A placebo-controlled experimental study. J. Orthop. Res. 2010, 28, 211-217.

2. Boswell S. G., Schnabel L. V., Mohammed H. O., Sundman E. A., Minas T., Fortier L. A.: Increasing platelet concentrations in leukocyte-reduced plateletrich plasma decrease collagen gene synthesis in tendons. Am. J. Sports Med. 2013, 42, 42-49.

3. Carr B. J. et al.: Canine Platelet-Rich Plasma Systems: A Prospective Analysis. Front. Vet. Sci. 2015, 2, 73

4. Castillo T. N., Pouliot M. A., Kim H. J., Dragoo J. L.: Comparison of growth factor and platelet concentrations from commercial platelet-rich plasma separation systems. Am. J. Sports Med. 2011, 39, 266-271.

5. Chahal J., Van Thiel G. S., Mall N., Heard W., Bach B. R., Cole B. J., Nicholson G. P., Verma N. N., Whelan D. B., Romeo A. A.: The Role of Platelet-Rich Plasma in Arthroscopic Rotator Cuff Repair: A Systematic Review With Quantitative Synthesis. The Journal of Arthroscopic \& Related Surgery 2012, 28, 1718-1727.

6. Dohan Ehrenfest D. M., Doglioli P., de Peppo G. M., Del Corso M., Charrier $J$. B.: Choukroun's platelet-rich fibrin (PRF) stimulates in vitro proliferation and differentiation of human oral bone mesenchymal stem cell in a dosedependent way. Arch. Oral Biol. 2010, 55, 185-194.

7. Fallouh L., Nakagawa K., Sasho T., Arai M., Kitahara S., Wada Y., Moriya H. Takahashi K.: Effects of autologous platelet-rich plasma on cell viability and collagen synthesis in injured human anterior cruciate ligament. J. Bone Joint Surg. Am. 2010, 92, 2909-2916.

8. Foster T. E., Puskas B. L., Mandelbaum B. R., Gerhardt M. B., Rodeo S. A.: Platelet-rich plasma: from basic science to clinical applications. Am. J. Sports Med. 2009, 37, 2259-2265

9. Franklin S. P., CookJ. L.: Prospective trial of autologous conditioned plasma versus hyaluronan plus corticosteroid for treatment of chronic elbow osteoarthritis in dogs. Can. Vet. J. 2013, 54, 881-884.

10. Franklin S. P., Garner B. C., CookJ. L.: Characteristics of canine platelet-rich plasma prepared with five commercially available systems. Am. J. Vet. Res. $2015,76,822-827$

11. Gawdat H. I., Hegazy R. A., Fawzy M. M., Fathy M.: Autologous Platelet Rich Plasma: Topical Versus Intradermal After Fractional Ablative Carbon Dioxide Laser Treatment of Atrophic Acne Scars. Dermatol. Surg. 2014, 40, 152-161.

12. Jeong K. I., Kim S. G., Oh J. S., Lee S. Y., Cho Y. S., Yang S. S., Park S. C., You J. S., Lim S. C., Jeong M. A., Kim J. S., Lee S. Y.: Effect of Platelet-Rich Plasma and Platelet-Rich Fibrin on Peri-Implant Bone Defects in Dogs. J. Biomed. Nanotechnol. 2013, 9, 535-537.

13. Karayannopoulou M., Psalla D., Kazakos G., Loukopoulos P., Giannakas N., Savvas I., Kritsepi-Konstantinou M., Chantes A., Papazoglou L. G.: Effect of locally injected autologous platelet-rich plasma on second intention wound healing of acute full-thickness skin defects in dogs. Vet. Comp. Orthop. Traumatol. 2015, 3, 172-178.

14. Lee D. K., In J., Lee S.: Standard deviation and standard error of the mean Korean J. Anesthesiol. 2015, 68, 220-223.

15.Li Z. J., Choi H. I., Choi D. K., Sohn K. C., Im M., Seo Y. J., Lee Y. H., Lee J. H., Lee $Y$ : Autologous platelet-rich plasma: a potential therapeutic tool for promoting hair growth. Dermatol. Surg. 2012, 38, 1040-1046.

16. Lubkowska A., Dolegowska B., Banfi G.: Growth factor content in PRP and their applicability in medicine. J. Biol. Regul. Homeost. Agents. 2012, 26, $22-25$.

17. Marx R. E., Carlson E. R., Eichstaedt R. M., Schimmele S. R., Strauss J. E., Georgeff K. R.: Platelet rich plasma: growth factor enhancement for bone grafts. Oral Surg. Oral Med. Oral Pathol. Oral Radiol. Endod. 1998, 85, 638-646.

18. McLellan J., Plevin S.: Does it matter which platelet-rich plasma we use? Equine Vet. Educ. 2011, 23, 101-104.

19. Mooren R. E., Hendriks E. J., van den Beucken J. J., Merkx M. A., Meijer G. J., Jansen J. A., Stoelinga P. J.: The effect of platelet-rich plasma in vitro on primary cells: rat osteoblast-like cells and human endothelial cells. Tissue Eng. Part A. 2010, 16, 3159-3172.

20.Lazzeri D., Nicoli F., Balzani A., Gentile P., Chilgar R. M., Di Pasquali C., Nicoli M., Bocchini I., Agovino A., Cervelli V.: Severe hidradenitis suppurativa treatment using platelet-rich plasma gel and Hyalomatrix. Int. Wound J. 2015, 12, 43-44.

21. Pelletier M. H., Malhotra A., Brighton T., Walsh W. R., Lindeman R.: Platelet function and constituents of platelet rich plasma. Int. J. Sports Med. 2013, 34, 74-80.

22. Sanchez-Gonzalez D. J., Mendez-Bolaina E., Trejo-Bahena N. I.: Platelet-rich plasma peptides: key for regeneration. Int. J. Pept. 2012, 3, 532-519.

23. Shin M. K., Lee J. H., Lee S. J., Kim N. I.: Platelet-rich plasma combined with fractional laser therapy for skin rejuvenation. Dermatol. Surg. 2012, 38, 623-630.

24. Stief M., GottschalkJ., Ionita J. C., Einspanier A., Oechtering G., Böttcher P. Concentration of platelets and growth factors in canine autologous conditioned plasma. Vet. Comp. Orthop. Traumatol. 2011, 24, 285-290.

25. Streckbein P., Kleis W., Buch R. S. R., Hansen T., Weibrich G.: Bone Healing with or without Platelet-Rich Plasma around Four Different Dental Implant Surfaces in Beagle Dogs. Clin. Implant. Dent. Relat. Res. 2014, 16, 479-486.

26. Sundman E. A., Cole B. J., Fortier L. A.: Growth factor and catabolic cytokine concentrations are influenced by the cellular composition of platelet-rich plasma. Am. J. Sports Med. 2011, 39, 2135-2140.

27. Textor J.: Platelet-Rich Plasma (PRP) as a Therapeutic Agent: Platelet Biology, Growth Factors and a Review of the Literature, [in:] Lana J. F. S. D., Santana A., Belangero D., Luzo M. (eds.): Platelet-Rich Plasma Regenerative Medicine: Sports Medicine, Orthopedics and Recovery of Musculoskeletal Injuries. XVII. Springer Pub. 2014.

28. Vasconcelos E., Figueiredo A. C., Seghatchian J.: Quality of platelet concentrates derived by platelet rich plasma, buffy coat and apheresis. Transfus. Apher. Sci. 2003, 29, 13-16.

29. Villela D. L., Santos V. L.: Evidence on the use of platelet-rich plasma for diabetic ulcer: a systematic review. Growth Factors 2010, 28, 111-116.

Correspondence: Prof. Yücel Meral, Ondokuz Mayıs University, Faculty of Veterinary Medicine, Department of Internal Medicine, Atakum, 55139 Samsun, Turkey; e-mail: ymeral@omu.edu.tr 